\title{
Polymorphisms in the TGFB1 and IL2RA genes are associated with clinical forms of leprosy in Brazilian population
}

\author{
Rodrigo Mendes de Camargo, ${ }^{1,2}$, Weber Laurentino da Silva ${ }^{1,2}$, Priscila Medeiros ${ }^{1,2}$, \\ Andrea de Faria Fernandes Belone ${ }^{1}$, Ana Carla Pereira Latini ${ }^{1,2} /+$ \\ 'Instituto Lauro de Souza Lima, Bauru, SP, Brasil \\ ${ }^{2}$ Universidade Estadual Paulista Júlio de Mesquita Filho, Faculdade de Medicina de Botucatu, Departamento de Doenças Tropicais e \\ Diagnóstico por Imagem, Botucatu, SP, Brasil
}

BACKGROUND Leprosy is a chronic infectious disease caused by Mycobacterium leprae, and compromises the skin and peripheral nerves. This disease has been classified as multibacillary (MB) or paucibacillary (PB) depending on the host immune response. Genetic epidemiology studies in leprosy have shown the influence of human genetic components on the disease outcomes.

OBJECTIVES We conducted an association study for IL2RA and TGFBI genes with clinical forms of leprosy based on two case-control samples. These genes encode important molecules for the immunosuppressive activity of Treg cells and present differential expressions according to the clinical forms of leprosy. Furthermore, IL2RA is a positional candidate gene because it is located near the $10 \mathrm{p} 13$ chromosome region, presenting a linkage peak for PB leprosy.

METHODS A total of 885 leprosy cases were included in the study; 406 cases from Rondonópolis County (start population), a hyperendemic region for leprosy in Brazil, and 479 cases from São Paulo state (replication population), which has lower epidemiological indexes for the disease. We tested 11 polymorphisms in the IL2RA gene and the missense variant rs 1800470 in the TGFBl gene.

FINDINGS The AA genotype of rs2386841 in $I L 2 R A$ was associated with the PB form in the start population. The AA genotype of rs1800470 in TGFB1 was associated with the MB form in the start population, and this association was confirmed for the replication population.

MAIN CONCLUSIONS We demonstrated, for the first time, an association data with the PB form for a gene located on chromosome 10. In addition, we reported the association of $T G F B 1$ gene with the MB form. Our results place these genes as candidates for validation and replication studies in leprosy polarisation.

Key words: leprosy - genetic epidemiology - TGFB1 - IL2RA - Tregs

Leprosy is a chronic infectious disease caused by Mycobacterium leprae, an intracellular pathogen with a predilection for skin macrophages and Schwann cells, causing skin lesions and compromising peripheral nerves. It represents a significant public health problem, where approximately 210,000 new cases are diagnosed annually. Brazil ranks second in the incidence of leprosy globally. ${ }^{(1)}$

The disease presents as a broad clinical spectrum between two poles, tuberculoid (TT) and lepromatous (LL), based on a predominance of the Th1 or Th2 immune response, respectively. The TT pole represents the localised form of the disease with the highest bacillus containment, and the LL pole represents the disseminated form with the highest bacillary spread. In addition, there are three intermediate forms: borderline tubercu-

doi: 10.1590/0074-02760180274

Financial support: FAPESP (grant no 2009/16873-8), Fundação Paulista

contra a Hanseníase.

+Corresponding author: anacarlap@gmail.com

Received 5 June 2018

Accepted 7 November 2018 loid (BT), borderline borderline (BB), and borderline lepromatous (BL). This classification, proposed by Ridley and Jopling, ${ }^{(2)}$ is widely used in research centres and covers clinical, immunological, microbiological, and histopathological aspects. However, for treatment purposes, the World Health Organization (WHO) has classified leprosy into paucibacillary (PB) and multibacillary (MB) since 1982. The first WHO classification considered PB as TT and BT patients with a 1+ bacilloscopic index..$^{(3)}$ Subsequently, WHO classified the PB cases only as those with a negative smear. ${ }^{(4)}$ Finally, in 1994, WHO classified PB and MB based on the number of lesions. ${ }^{(5)}$

Although several studies have demonstrated the participation of host genetic components in leprosy per se development, few studies have investigated the markers associated with the clinical forms of the disease. The number of genes associated with leprosy subtypes or its polarisation (39 associations in 28 genes) is lower than to leprosy per se (82 associations in 50 genes). ${ }^{(6)} \mathrm{In}$ most cases, the association analyses of clinical forms are secondary to studies about leprosy per se and are often comparisons of clinical form groups to healthy controls. However, as discussed by Gaschignard and colleagues, ${ }^{(6)}$ these designs inappropriately consider the PB and MB forms of leprosy as "distinct diseases". Further, the mechanisms involved in the disease per se are not necessarily involved in the determination of the clinical form. 
(6) In addition, a two-stage model has been proposed to assess genetic susceptibility to leprosy, which includes a set of genes to determine the risk of leprosy per se and another set to determine the clinical form of leprosy. ${ }^{(7)}$

The following genes were determined to have replicated and/or validated associations with clinical forms of leprosy: 1) $T N F$, associated with the MB form in Indian ${ }^{(8)}$ and Thai populations, ${ }^{(9)}$ 2) $M R C 1$ and $M B L 2$, associated with the MB form in Brazil ${ }^{(10,11)}$ and Nepal, ${ }^{(12)}$ and to the PB form in China, ${ }^{(13,14)}$ 3) TLR2, associated with the PB form in Ethiopia ${ }^{(15)}$ and Malawi and 4) LRRK2 associated with the PB form in China ${ }^{(16)}$ and India. ${ }^{(17)}$ Besides, several studies have produced replicated association data for clinical forms of leprosy in the Chinese population. ${ }^{(13,14,18,19,20,21,22,23)}$ From linkage scans in two studies, one peak at chromosomal region 10p13 for PB leprosy was discovered. ${ }^{(24,25)}$

The IL2RA gene, which encodes the alpha subunit of the IL-2 receptor, is known as CD25. It is a functional and positional candidate gene for the clinical forms of leprosy as it is located at the chromosomal region 10p15, near the linkage peak for PB leprosy. ${ }^{(24,25)} \mathrm{CD} 25$ is also an important marker of regulatory $\mathrm{T}$ cells (Tregs), which regulate the induction and maintenance of immunosuppression in lepromatous leprosy. ${ }^{(26)}$ High numbers of $\mathrm{CD} 25+$ cells are found in patients of the lepromatous pole and are associated with $M$. leprae proliferation. $(27,28)$ The nature of FOXP3 activity, whether inhibiting or activating, appears to differ when comparing leprosy poles. ${ }^{(29)}$ In addition, in lepromatous patients, miR155, which is involved in higher proliferation and longevity of Tregs, ${ }^{(29)}$ is seen to be overexpressed. Notably, Treg cells use this receptor to consume IL-2 at the site of the immune response, which hinders activation and proliferation of effector $\mathrm{T}$ lymphocytes and prevents activation of macrophages. ${ }^{(30)}$

The TGF- $\beta$ is a pleiotropic cytokine, and it is an important effector molecule for the immunoregulatory activity of Tregs. ${ }^{(31)}$ It plays an important role in diseases caused by intracellular microorganisms, such as Leishmania, Trypanosoma cruzi, Toxoplasma gondii, Lacazia loboi, and mycobacteria, as it suppresses macrophage activation. ${ }^{(32)}$ In vitro and in situ studies confirm higher TGF- $\beta$ production in lepromatous patients, which contributes to the anti-inflammatory milieu and bacillary persistence observed at this pole. ${ }^{(32,33,34,35)}$

Applying the strategy proposed by Gaschignard and researchers ${ }^{(6)}$ we conducted an association study of $I L$ $2 R A$ and $T G F B 1$ candidate genes in the "leprosy polarisation" phenotype, as this is a needy focus of inquiry in genetic epidemiology of leprosy.

\section{SUBJECTS AND METHODS}

Subjects and study design - We applied a step-wise strategy based on two Brazilian cohorts. We investigated eleven markers at IL2RA gene and one marker at TGFBI gene in a start population. Then, the markers reaching Bonferroni-corrected p-value threshold significance were tested in the replication population.

Our start population was sampled from Rondonópolis County, located at Mato Grosso state, a hyperendemic region for leprosy in Brazil. The replication population is from the state of São Paulo, where the epidemiological indices of leprosy are more controlled. ${ }^{(36)}$

To classify patients as $\mathrm{PB}$ and MB, we adopted the WHO classification criterion of $1982 .^{(3)}$ Taking into account the Ridley and Jopling ${ }^{(2)}$ spectrum, TT and BT patients with $\leq 1+$ bacilloscopic indices were classified as $\mathrm{PB}$, while those with bacilloscopic indices $\geq 2+$ were classified as MB.

Patients from Rondonópolis included 406 individuals, of which 90 were PB and $310 \mathrm{MB}$. Leprosy diagnosis was confirmed by clinical laboratory tests in the outpatient service of the local family health clinics. São Paulo state enrolled 479 patients diagnosed at the Lauro de Souza Lima Institute (Bauru SP), of which 99 were $\mathrm{PB}$ and 380 were $\mathrm{MB}$.

As a control for ethnicity in the association study, we defined the molecular ancestry for the start population by employing 46 ancestry informative indels, as previously described. ${ }^{(37)}$ The estimates of individual ancestry, European, African, and Native American were analysed using the ADMIXTURE software. ${ }^{(38)}$ The admixture fraction mean values were $0.58,0.27$, and 0.15 in cases and $0.58,0.25$, and 0.17 in controls for European, African, and Native American ancestries, respectively. The descriptions of the general characteristics of these groups are detailed in the Table I.

DNA extraction and SNP genotyping - Genomic DNA was extracted from peripheral blood leukocyte samples using the salting-out method. Genotyping was performed by the allelic discrimination method based on TaqMan ${ }^{\circledR}$ technology (Applied Biosystems, Foster City, CA, USA) and was carried out using the Step One Plus real-time PCR equipment (Applied Biosystems, Foster City, CA, USA).

Markers selection - The rs 1800470 polymorphism of the $T G F B 1$ gene was selected based on the data from the literature, which reported the functional effects of this variant. ${ }^{(39,40,41,42,43,44,45,46,47)}$ This is a missense polymorphism, which promotes a proline to leucine substitution at the 10th residue.

For the IL2RA gene, 11 tag SNPs were selected from the International HapMap Project database, taking the minimum minor allele frequency of 0.1 and an $\mathrm{r}^{2}$ cutoff of 0.8 in the Yoruba population as parameters. ${ }^{(48)}$ The following SNPs were selected: rs7910961, rs11256497, rs12722561, rs2245675, rs2386841, rs3134883, rs4749926, rs6602392, rs706778, rs942201, and rs9663421.

Statistical analyses - The comparisons of allele, genotype, and carrier frequencies were performed using an univariate logistic regression model, with and without adjustment for the sex, as previously described. ${ }^{(49)}$ For the start population, we also used the molecular ancestry as a covariate in the regression model. From the indels data, we have employed ADMIXTURE software to estimate European, African, and Native American ancestries. ${ }^{(38)}$ So, we used these data for a continuous adjustment since there is not a consensus on the use of these continuous variables to classify ethnicity as a categorical variable. All analyses were performed using the statistical software $\mathrm{R}$ for Windows, version 2.5.1, and the package Genetics. 
TABLE I

Characteristics of multibacillary leprosy $(\mathrm{MB})$ and paucibacillary leprosy (PB) groups in the start and replication populations

\begin{tabular}{lccc}
\hline Variable & Category & $\begin{array}{c}\text { Start population } \\
(\mathrm{n}=406)\end{array}$ & $\begin{array}{c}\text { Replication population } \\
(\mathrm{n}=479)\end{array}$ \\
\hline Clinical form (WHO, 1982) & Paucibacillary & $96(24 \%)$ & $99(21 \%)$ \\
& Multibacillary & $310(76 \%)$ & $380(79 \%)$ \\
Clinical form (Ridley \& Jopling, 1966) & LL & $21(5.1 \%)$ & $102(21.2 \%)$ \\
& BL & $63(15.3 \%)$ & $131(27.3 \%)$ \\
& BB & $79(19.2 \%)$ & $132(27.5 \%)$ \\
Age (mean \pm SD) MB & BT & $156(38.7 \%)$ & $49(10.2 \%)$ \\
Age (mean \pm SD) PB & TT & $60(14.6 \%)$ & $62(12.9 \%)$ \\
Sex MB & IL & $27(6.6 \%)$ & $3(0.6 \%)$ \\
Sex PB & & $42.9 \pm 16.1$ & $37.9 \pm 18.01$ \\
& Male & $39.1 \pm 16.1$ & $40.2 \pm 18.01$ \\
& Female & $201(65 \%)$ & $271(71 \%)$ \\
\end{tabular}

BB: bordeline bordeline leprosy; BL: borderline lepromatous leprosy; BT: borderline tuberculoid leprosy; IL: indeterminate leprosy; LL: polar lepromatous leprosy; SD: standard deviation; TT: polar tuberculoid leprosy.

In order to avoid the multiple comparisons effect, Bonferroni correction was adopted before testing the markers in the replication population.

To evaluate signal independence for markers at $I L 2 R A$, we measured linkage disequilibrium (LD) using the Haploview software, version 4.2. ${ }^{(50)}$ We used the Solid Spine of LD algorithm to define the blocks, using a D-value cut-off of 0.8 .

The call rate $>0.95$ was adopted as the quality control parameter, and all the polymorphisms met these criteria.

\section{RESULTS}

3.1. SNP rs2386841 of the IL2RA gene is associated with $P B$ leprosy - Eleven markers at the IL2RA gene were tested in the start population, and rs2386841 and rs6602392 markers presented positive signal (Table II, Supplementary data).

The LD plot for these eleven IL2RA markers revealed four blocks of LD and two singleton SNPs (Figure). To test SNPs in the replication population, we applied the Bonferroni correction as described by Duggal and colleagues, ${ }^{(51)}$ since SNPs at the same block are not considered independent. Thus, considering four models (two genotypic, one allelic and one carrier of minor allele) and six hypotheses (four haplotype blocks and two independent markers), the p-value threshold for IL2RA gene was found to be 0.002 .

The adjusted data for the AA genotype of the rs2386841 [Odds ratio (OR): 5.45, Confidence interval (CI) 95\%: 1.93-15.3, p-value: 0.0013] marker remained significantly associated with the PB leprosy after correction. Further, it was tested in the replication population, according to the step-wise strategy. However, this association was not replicated in the replication population, as described in Table II.
For the carriers of allele A at the rs6602392 marker, the p-value of 0.0271 did not reach significance after correction, and it was not tested in the replication population.

SNP rs1800470 of the TGFB1 gene is associated with $M B$ leprosy - For the start population, the rs 1800470 marker in the TGFB1 gene was tested. The adjusted data demonstrated an association of the AA genotype (OR: 2.81, CI95\%: 1.27-6.24, p-value: 0.0107) with the MB form of the disease. This association persisted even after applying Bonferroni correction, following the same strategy as for $I L 2 R A$ gene (p-value $<0.0125$ ), and this

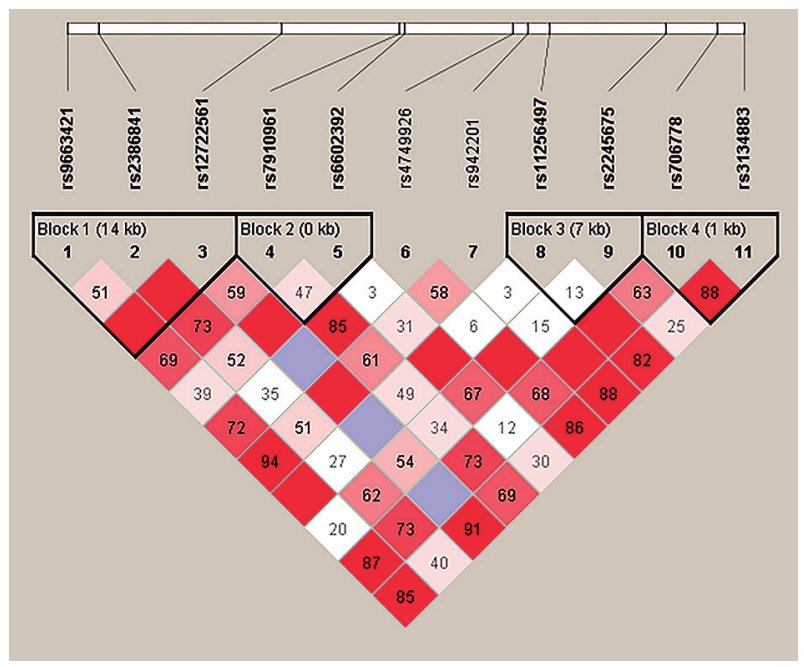

Linkage disequilibrium (LD) map for eleven SNPs at IL2RA gene genotyped for the start population. The number within boxes represents D-values calculated by Haploview software (4.2). The blocks were defined by Solid Spine of LD algorithm. 
TABLE II

Frequency data in paucibacillary leprosy $(\mathrm{PB})$ and multibacillary leprosy $(\mathrm{MB})$ groups and association data for the markers rs2386841 and rs6602392 at the IL2RA gene

\begin{tabular}{|c|c|c|c|c|c|}
\hline Population/marker & $\begin{array}{c}\text { Alelles } \\
\text { or genotypes }\end{array}$ & PB & MB & OR $(95 \% \mathrm{CI}) \mathrm{p}$-value & OR $(95 \% \mathrm{CI}) \mathrm{p}$-value ${ }^{a}$ \\
\hline Start population & $\mathrm{C}$ & 0.76 & 0.83 & $*$ & $*$ \\
\hline \multirow[t]{6}{*}{ rs2386841 } & A & 0.24 & 0.17 & $1.57(0.89-2.75) 0.1150$ & $1.80(0.98-3.27) 0.0546$ \\
\hline & $\mathrm{CC}$ & $59(0.62)$ & $214(0.70)$ & $*$ & $*$ \\
\hline & $\mathrm{AC}$ & $27(0.28)$ & $83(0.27)$ & 1.17 (1.37-9.54) 0.5338 & $1.23(0.70-2.17) 0.4613$ \\
\hline & $\mathbf{A A}$ & $9(0.09)$ & $9(0.03)$ & $3.62(1.37-9.54) 0.0091$ & $5.45(1.93-15.3) 0.0013$ \\
\hline & Carrier A & & & $1.41(0.87-2.29) 0.1538$ & $1.57(0.93-2.64) 0.0860$ \\
\hline & & $\mathrm{n}=95$ & $\mathrm{n}=306$ & & \\
\hline Start population & $\mathrm{C}$ & 0.89 & 0.82 & $*$ & $*$ \\
\hline \multirow[t]{6}{*}{ rs6602392 } & $\mathrm{A}$ & 0.11 & 0.18 & $0.55(0.26-1.16) 0.1189$ & $0.49(0.23-1.05) 0.0669$ \\
\hline & $\mathrm{CC}$ & $74(0.78)$ & $209(0.68)$ & $*$ & $*$ \\
\hline & $\mathrm{AC}$ & $21(0.22)$ & $86(0.28)$ & $0.66(0.37-1.17) 0.1626$ & $0.60(0.33-1.07) 0.0873$ \\
\hline & AA & 0 & $11(0.04)$ & - & - \\
\hline & Carrier A & & & $0.58(0.33-1.03) 0.0643$ & $0.52(0.29-0.92) 0.0271$ \\
\hline & & $\mathrm{n}=95$ & $\mathrm{n}=306$ & & \\
\hline Replication population & $\mathrm{C}$ & 0.76 & 0.74 & * & $*$ \\
\hline \multirow[t]{6}{*}{ rs 2386841} & $\mathrm{~A}$ & 0.24 & 0.26 & $0.91(0.50-1.65) 0.7683$ & $0.90(0.49-1.62) 0.7322$ \\
\hline & $\mathrm{CC}$ & $44(0.59)$ & $175(0.58)$ & $*$ & $*$ \\
\hline & $\mathrm{AC}$ & $24(0.32)$ & $97(0.32)$ & $0.98(0.56-1.71) 0.9548$ & $0.96(0.54-1.67) 0.8889$ \\
\hline & AA & $6(0.08)$ & $30(0.10)$ & $0.79(0.31-2.02) 0.6321$ & $0.78(0.30-2.00) 0.6133$ \\
\hline & Carrier A & & & $0.93(0.56-1.57) 0.8131$ & $0.91(0.54-1.54) 0.7517$ \\
\hline & & $\mathrm{n}=74$ & $\mathrm{n}=302$ & & \\
\hline
\end{tabular}

Bold values denote statistically significant results.*: indicates the baseline for comparison; $a$ : Odds ratio (OR) e p-value adjusted for covariates sex and individual ancestry for start population and sex for replication population; CI: confidence interval. Global $\mathrm{p}$-values (general test): $\mathrm{rs} 2386841$ - start population $(\mathrm{p}=0.02)$, rs6602392 - start population $(\mathrm{p}=0.02)$.

data was replicated in the replication population. In addition, the carriers of the A allele showed associations with the MB form in the replication population, as described in Table III.

A combined analysis of both the populations, with adjustment for sex and origin covariates, was conducted. From this analysis, the association of the AA genotype with the MB form was confirmed (OR: 2.23, CI95\%: 1.35-3.66, p-value: 0.0016). In addition, the A allele, and $\mathrm{A}$ carriers were associated with the MB form, as described in Table III.

\section{DISCUSSION}

Following tests of 11 polymorphisms covering the $I L$ $2 R A$ gene, we found that the AA genotype of rs2386841 was associated with susceptibility to the PB form in the start population. This is the second loci near the $10 \mathrm{p} 13$ region, associated with the $\mathrm{PB}$ form, which is supported by the findings from two linkage studies. ${ }^{(24,25)}$ Notably, the first associated gene, $M R C 1$, had markers associated with PB leprosy in China, while it was associated with the MB form in Brazil and Vietnam. ${ }^{(10,13)}$ Moreover, the other associations described in this region, at $N E B L$ and
$C U B N$ genes, were also related to the MB form. ${ }^{(52)}$ Thus, our data inserted a new candidate gene at this region, associated with the polarisation phenotype outcome.

Polymorphisms at the IL2RA gene are associated with lesion development in cutaneous leishmaniasis in Brazilian populations. ${ }^{(53)}$ In addition, the authors demonstrated a functional role for the associated alleles by decreasing the IFN- $\gamma$ response and the Treg cell activities, which are closely related to the leprosy manifestations. Our results, coupled with Oliveira and colleagues, provide strong evidence of the importance of the IL2RA gene for the severity of infectious diseases caused by intracellular parasites. ${ }^{(53)}$ In order to reinforce this role, a relevant meta-analysis confirmed $I L 2 R A$ as a susceptibility gene for Crohn's Disease, which shares genetic risk factors with leprosy. ${ }^{(54,55)}$

When testing the TGFB1 gene, we found an association between the AA genotype of the polymorphism rs1800470 to the risk of MB leprosy in both populations. The combined analysis with adjustments reinforced this association effect. This variant, also known as +29C $>\mathrm{T}$, is located at the hydrophobic core of the signal peptide sequence; however, both alleles encode non-polar amino 
TABLE III

Frequency data in paucibacillary leprosy (PB) and multibacillary leprosy (MB) groups and association data for the marker rs1800470 at the TGFB1 gene

\begin{tabular}{|c|c|c|c|c|c|}
\hline Population & $\begin{array}{c}\text { Alelles } \\
\text { or genotypes }\end{array}$ & PB & MB & OR $(95 \% \mathrm{CI}) \mathrm{p}$-value & OR $(95 \%$ CI $)$ p-value ${ }^{a}$ \\
\hline \multirow[t]{7}{*}{ Start population } & $\mathrm{G}$ & 0.55 & 0.45 & $*$ & $*$ \\
\hline & A & 0.45 & 0.55 & $1.49(0.92-2.41) 0.0999$ & $1.57(0.94-2.63) 0.0796$ \\
\hline & GG & $24(0.27)$ & $54(0.19)$ & $*$ & $*$ \\
\hline & $\mathrm{AG}$ & $50(0.56)$ & $146(0.52)$ & $1.29(0.72-2.31) 0.3770$ & $1.32(0.72-2.43) 0.3545$ \\
\hline & $\mathbf{A A}$ & $15(0.17)$ & $83(0.29)$ & $2.45(1.18-5.10) 0.0158$ & $2.81(1.27-6.24) 0.0107$ \\
\hline & Carrier A & & & $1.56(0.89-2.72) 0.1127$ & $1.63(0.91-2.93) 0.0963$ \\
\hline & & $\mathrm{n}=89$ & $\mathrm{n}=283$ & & \\
\hline \multirow[t]{7}{*}{ Replication population } & G & 0.53 & 0.45 & $*$ & $*$ \\
\hline & A & 0.47 & 0.55 & $1.40(0.87-2.26) 0.1650$ & $1.40(0.87-2.27) 0.1637$ \\
\hline & GG & $25(0.30)$ & $68(0.20)$ & $*$ & $*$ \\
\hline & $\mathrm{AG}$ & $39(0.46)$ & $174(0.50)$ & $1.64(0.92-2.91) 0.0917$ & $1.66(0.93-2.96) 0.0845$ \\
\hline & $\mathbf{A A}$ & $20(0.24)$ & $106(0.30)$ & $1.94(1.00-3.77) 0.0483$ & $1.96(1.00-3.81) 0.0472$ \\
\hline & Carrier A & & & $1.74(1.01-2.98) 0.0424$ & $1.76(1.02-3.03) 0.0394$ \\
\hline & & $\mathrm{n}=84$ & $\mathrm{n}=348$ & & \\
\hline \multirow[t]{6}{*}{ Combined populations } & $\mathrm{G}$ & 0.54 & 0.45 & $*$ & $*$ \\
\hline & $\mathbf{A}$ & 0.46 & 0.55 & $1.45(1.03-2.04) 0.0294$ & $1.45(1.03-2.04) 0.0306$ \\
\hline & GG & $49(0.28)$ & $122(0.19)$ & $*$ & $*$ \\
\hline & $\mathrm{AG}$ & $89(0.51)$ & $320(0.51)$ & $1.44(0.96-2.16) 0.0763$ & $1.47(0.97-2.22) 0.0636$ \\
\hline & $\mathbf{A A}$ & $35(0.20)$ & $189(0.30)$ & $2.16(1.32-3.53) 0.0020$ & $2.17(1.32-3.57) 0.0020$ \\
\hline & Carrier A & & & $1.64(1.12-2.42) 0.0110$ & $1.67(1.13-2.47) 0.0095$ \\
\hline
\end{tabular}

Bold values denote statistically significant results.*: indicates the baseline for comparison; $a$ : Odds ratio (OR) e p-value adjusted for covariates sex and individual ancestry for start population; sex for replication population; sex and origin for combined populations; CI: confidence interval. Global p-values (general test): rs1800470 - start population $(\mathrm{p}=0.02)$, rs1800470 - replication population (0.12), combined populations $(\mathrm{p}=0.01)$.

acids. ${ }^{(47)}$ Our findings are in conflict with the functional data, suggesting that the $G$ allele is associated with higher production of TGF- $\beta 1^{(47)}$ since MB patients have higher levels of this cytokine. ${ }^{(34,35)}$ In vitro studies using different infection ratios as stimuli and considering the different genotypes for rs1800470 may be an interesting strategy to better explain this genetic data in leprosy polarisation.

According to the $2016 \mathrm{WHO}$ data, $72 \%$ of new Brazilian leprosy cases were MB. ${ }^{(56)}$ Therefore, $76 \%$ of MB cases in our both study populations reflect the leprosy epidemiology in Brazil. Despite similar distributions, we observed major representation of the BL and LL categories in the replication population and overrepresentation by the BT form in the start population. This is a limitation of our study, but it can help explain the replication of the TGFB1 association with the MB form and the non-replication of the $I L 2 R A$ association with the PB form. This also reinforces the necessity for more investigations focusing on the IL2RA gene.

Classical variables influencing the outcome of clinical forms of leprosy are sex, endemicity, geography, age, and BCG vaccination. ${ }^{(6)}$ To control for biases, we adopt- ed selection criteria and analysis parameters to account for the effects of these covariates. Although ethnicity is not a classical risk factor influencing clinical forms of leprosy, human genetic factors influence the effect associated to the geography and endemicity. Thus, we considered ethnicity in our analysis due to the diverse admixture of races in Brazil, relative to the region of the country. Although the ancestry data revealed no substantial distortion between cases and controls, they were used to adjust the analysis in order to control some bias due to this variable in our study. Data from the literature indicated a higher incidence of the MB form in men than in women, with a ratio of $1.5-2 .^{(6)}$ The number of MB individuals is also higher in Brazilian men than women. ${ }^{(56)}$ Our population samples followed this observation since the male: female ratios in the MB groups were 1.84 for the start population and 2.48 for the replication population. When adjusting our analysis using sex and ancestry data as covariates, we observed a stronger association effect for rs 2386841 at $I L 2 R A$. This confirms the importance of considering these covariates when studying leprosy polarisation outcome. 
A higher mean age of $\mathrm{MB}$, relative to $\mathrm{PB}$ patients has also been reported, which is likely due to the long incubation time of the bacillus. ${ }^{(56,57,58)}$ Although the influence of age is higher in men than in women, the effect of these covariates (age and sex) are independent in leprosy polarisation. ${ }^{(58)}$ In our study, the mean age of illness for both populations is consistent with observations from the Brazilian population, which has a predominance of adult cases. ${ }^{(56)}$ Moreover, we did not observe relevant differences in age between PB and MB cases.

Leprosy is a complex trait and factors related to the host, environment, and pathogen act in the development of the disease per se and its clinical forms. ${ }^{(7)}$ However, there is no evidence that different strains of M. leprae interfere in the leprosy outcome; also, studies suggest low genetic variability of the bacillus. ${ }^{(59)}$ Therefore, considering the broad clinical spectrum of leprosy, the human genetic component seems to play a more relevant role in the outcome of the disease. ${ }^{(7)}$ From the epidemiological perspective, clarifying which host genetic factors are involved in leprosy polarisation may help predict clinical forms with higher potential to transmit disease, thus helping interrupt the transmission chain. As a result, our data points to IL2RA and TGFBI associations with leprosy polarisation and help to construct the genetic architecture of this neglected phenotype.

\section{ACKNOWLEDGEMENTS}

To Ohanna Cavalcanti Bezerra and Lucia Elena Alvarado Arnez for helping with the analyses, and Milton Ozório Moraes for the critical reading of the manuscript.

\section{AUTHORS' CONTRIBUTION}

RMC - Conducted most of the experiments and analysed the results; WLS and PM - helped with the experiments and data management; AFFB - recruited leprosy patients and collected samples; ACPL - contributed to the study design, coordination, and wrote the paper.

\section{REFERENCES}

1. WHO - World Health Organization. Global leprosy update, 2017: reducing the disease burden due to leprosy. WER. 2018; 93(35): 445-56.

2. Ridley DS, Jopling WH. Classification of leprosy according to immunity: a five-group system. Int J Lep. 1966; 34(3): 255-73.

3. WHO - World Health Organization. Chemotherapy of leprosy for control programmes: report of a WHO study group [meeting held in Geneva from 12 to 16 October 1981]. Geneva: World Health Organization; 1982. Available from: http://www.who.int/iris/handle/10665/38984.

4. WHO - World Health Organization. Expert committee on leprosy: fifth report. Technical report series 678. Geneva: World Health Organization; 1988.

5. WHO - World Health Organization. Chemotherapy of leprosy: report of a WHO study group [meeting held in Geneva from 1 to 5 November 1993]. Geneva: World Health Organization; 1994.

6. Gaschignard J, Grant AV, Van Thuc N, Orlova M, Cobat A, Huong NT, et al. Pauci- and multibacillary leprosy: two distinct, genetically neglected diseases. PLoS Negl Trop Dis. 2016; 10(5): 1-20.

7. Alter A, Grant A, Abel L, Alcais A, Schurr E. Leprosy as a genetic disease. Mamm. Genome. 2011; 22(1-2): 19-31.
8. Roy S, McGuire W, Mascie-Taylor CG, Saha B, Hazra SK, Hill AV, et al. Tumor necrosis factor promoter polymorphism and susceptibility to lepromatous leprosy. J Infect Dis. 1997; 176(2): 530-2.

9. Vejbaesya S, Mahaisavariya P, Luangtrakool P, Sermduangprateep C. TNF $\alpha$ and NRAMP1 polymorphisms in leprosy. J Med Assoc Thai. 2007; 90(6): 1188-92.

10. Alter A, De Léséleuc L, Van Thuc N, Thai VH, Huong NT, Ba NN, et al. Genetic and functional analysis of common MRC1 exon 7 polymorphisms in leprosy susceptibility. Hum Genet. 2010; 127(3): 337-48.

11. de Messias-Reason IJ, Boldt ABW, Braga ACM, Stahlke ERS, Dornelles L, Pereira-Ferrari L, et al. The association between mannan-binding lectin gene polymorphism and clinical leprosy: new insight into an old paradigm. J Infect Dis. 2007; 196: 1379-85.

12. Sapkota BR, Macdonald M, Berrington WR, Misch EA, Ranjit C, Siddiqui MR, et al. Association of TNF, MBL, and VDR polymorphisms with leprosy phenotypes. Hum Immunol. 2010; 71(10): 992-8.

13. Wang D, Feng JQ, Li YY, Zhang DF, Li XA, Li QW, et al. Genetic variants of the MRC1 gene and the IFNG gene are associated with leprosy in Han Chinese from Southwest China. Hum Genet. 2012; 131(7): $1251-60$

14. Zhang DF, Huang XQ, Wang D, Li YY, Yao YG. Genetic variants of complement genes ficolin-2, mannose-binding lectin and complement factor $\mathrm{H}$ are associated with leprosy in Han Chinese from Southwest China. Hum Genet. 2013; 132(6): 629-40.

15. Bochud P, Hawn TR, Siddiqui MR, Saunderson P, Britton S, Abraham I, et al. Toll-Like Receptor 2 (TLR2) polymorphisms are associated with reversal reaction in leprosy. J Infect Dis. 2008; 197(2): 253-61.

16. Wang D, Xu L, Lv L, Su LY, Fan Y, Zhang DF, et al. Association of the LRRK2 genetic polymorphisms with leprosy in Han Chinese from Southwest China. Genes Immun. 2015; 16(2): 112-9.

17. Marcinek P, Jha AN, Shinde V, Sundaramoorthy A, Rajkumar R, Suryadevara NC, et al. LRRK2 and RIPK2 variants in the NOD 2-mediated signaling pathway are associated with susceptibility to Mycobacterium leprae in Indian populations. PLoS One. 2013; 8(8): e73103.

18. Zhang DF, Wang D, Li YY, Yao YG. Mapping genetic variants in the CFH gene for association with leprosy in Han Chinese. Genes Immun. 2014; 15(7): 506-10.

19. Li GD, Wang D, Zhang DF, Xiang Q, Feng JQ, Li XA, et al. Fine mapping of the GWAS loci identifies SLC35D1 and IL23R as potential risk genes for leprosy. J Dermatol Sci. 2016; 84(3): 322-9.

20. Wang D, Zhang DF, Feng JQ, Li GD, Li XA, Yu XF, et al. Common variants in the PARL and PINK1 genes increase the risk to leprosy in Han Chinese from South China. Sci Rep. 2016; 6: 37086.

21. Wang D, Li GD, Fan Y, Zhang DF, Bi R, Yu XF, et al. The mtDNA replication-related genes TFAM and POLG are associated with leprosy in Han Chinese from Southwest China. J Dermatol Sci. 2017; 88(3): 349-56.

22. Wang D, Zhang DF, Li GD, Bi R, Fan Y, Wu Y, et al. A pleiotropic effect of the APOE gene: association of APOE polymorphisms with multibacillary leprosy in Han Chinese from Southwest China. Br J Dermatol. 2018; 178(4): 931-9.

23. Wang D, Fan Y, Malhi M, Bi R, Wu Y, Xu M, et al. Missense variants in HIF1A and LACC1 contribute to leprosy risk in Han Chinese. Am J Hum Genet. 2018; 102(5): 794-805.

24. Mira MT, Alcaïs A, Van Thuc N, Thai VH, Huong NT, Ba NN, et al. Chromosome 6q25 is linked to susceptibility to leprosy in a Vietnamese population. Nat Genet. 2003; 33(3): 412-5. 
25. Siddiqui MR, Meisner S, Tosh K, Balakrishnan K, Ghei S, Fisher $\mathrm{SE}$, et al. A major susceptibility locus for leprosy in India maps to chromosome 10p13. Nat Genet. 2001; 27(4): 439-41.

26. Sadhu S, Khaitan BK, Joshi B, Sengupta U, Nautiyal AK, Mitra DK. Reciprocity between regulatory $\mathrm{T}$ cells and Th17 cells: relevance to polarised immunity in leprosy. PLoS Negl Trop Dis. 2016; 10(1): e0004338.

27. Tarique M, Saini C, Naqvi RA, Khanna N, Sharma A, Rao DN. IL-12 and IL-23 modulate plasticity of FoxP3+ regulatory T cells in human leprosy. Mol Immunol. 2017; 83: 72-81.

28. Bobosha K, Wilson L, van Meijgaarden KE, Bekele Y, Zewdie M, van der Ploeg-van Schip JJ, et al. T-cell regulation in lepromatous leprosy. PLoS Negl Trop Dis. 2014; 8(4): e2773.

29. Kumar S, Naqvi RA, Ali R, Rani R, Khanna N, Rao DN. $\mathrm{CD} 4+\mathrm{CD} 25+\mathrm{T}$ regs with acetylated FoxP3 are associated with immune suppression in human leprosy. Mol Immunol. 2013; 56(4): 513-20.

30. Chinen T, Kannan AK, Levine AG, Fan X, Klein U, Zheng Y, et al. An essential role for the IL-2 receptor in T reg cell function. Nat Immunol. 2016; 17(11): 1322-33.

31. Massagué J. TGF $\beta$ signalling in context. Nat Rev Mol Cell Biol. 2012; 13(10): 616-30

32. Aarão TLS, Esteves NR, Esteves N, Soares LPM, Pinto DS, Fuzii HT, et al. Relationship between growth factors and its implication in the pathogenesis of leprosy. Microb Pathog. 2014; 77: 66-72.

33. Petito RB, Amadeu TP, Pascarelli BMO, Jardim MR, Vital RT, Antunes SL, et al. Transforming growth factor- $\beta 1$ may be a key mediator of the fibrogenic properties of neural cells in leprosy. $\mathrm{J}$ Neuropathol Exp Neurol. 2013; 72(4): 351-66.

34. Saini C, Ramesh V, Nath I. Increase in TGF-B1 Secreting CD4+CD25+ FOXP3+ T regulatory cells in anergic lepromatous leprosy patients. PLoS Negl Trop Dis. 2014; 8(1): e2639.

35. Venturini J, Soares CT, Belone ADFF, Barreto JA, Ura S, Lauris JRP, et al. In vitro and skin lesion cytokine profile in Brazilian patients with borderline tuberculoid and borderline lepromatous leprosy. Lepr Rev. 2011; 82: 25-35.

36. SVS/MS - Secretaria de Vigilância em Saúde/Ministério da Saúde. Caracterização da situação epidemiológica da hanseníase e diferenças por sexo, Brasil, 2012-2016. Bol Epidemiol. 2018; 49(4): 1-10.

37. Pereira R, Phillips C, Pinto N, Santos C, dos Santos SEB, Amorim A, et al. Straightforward inference of ancestry and admixture proportions through ancestry-informative insertion deletion multiplexing. PLoS One. 2012; 7(1): e29684.

38. Alexander DH, Novembre J, Lange K. Fast model-based estimation of ancestry in unrelated individuals. Genome Res. 2009; 19(9): 1655-64.

39. Shin A, Shu XO, Cai Q, Gao YT, Zheng W. Genetic polymorphisms of the transforming growth factor-betal gene and breast cancer risk: a possible dual role at different cancer stages. Cancer Epidemiol Biomarkers Prev. 2005; 14(6): 1567-70.

40. Wei Y, Zhu Y, Du B, Yang Z, Liang W, Lv M, et al. Association of transforming growth factor-betal gene polymorphisms with genetic susceptibility to nasopharyngeal carcinoma. Clin Chim Acta. 2007; 380(1-2): 165-9.

41. Li Z, Habuchi T, Tsuchiya N, Mitsumori K, Wang L, Ohyama C, et al. Increased risk of prostate cancer and benign prostatic hyperplasia associated with transforming growth factor-beta 1 gene polymorphism at codon10. Carcinogenesis. 2004; 25(2): 237-40.
42. Fan $H, Y u H$, Deng $H$, Chen $X$. Transforming growth factor- $\beta 1$ rs 1800470 polymorphism is associated with lung cancer risk: a meta-analysis. Med Sci Monit. 2014; 20: 2358-62.

43. Zhang L, Mao L, Xu J. Transforming growth factor- $\beta 1$ polymorphisms and graft-versus-host disease risk: a meta-analysis. Oncotarget. 2015; 7(3): 2455-61.

44. Langdahl BL, Uitterlinden AG, Ralston SH, Trikalinos TA, Balcells S, Brandi ML, et al. Large-scale analysis of association between polymorphisms in the transforming growth factor beta 1 gene (TGFB1) and osteoporosis: The GENOMOS study. Bone. 2008; 42(5): 969-81.

45. Sandhya A, Bindu CH, Reddy KP, Vishnupriya S. TGFB1 codon 10 polymorphism and its association with the development of myopia: A case-control study. Biol Med. 2011; 3(4): 18-24.

46. Jonth AC, Silveira L, Fingerlin TE, Sato H, Luby JC, Welsh KI, et al. TGF-beta 1 variants in chronic beryllium disease and sarcoidosis. J Immunol. 2007; 179(6): 4255-62.

47. Cebinelli GCM, Trugilo KP, Garcia SB, de Oliveira KB. TGF- $\beta 1$ functional polymorphisms: a review. Eur Cytokine Netw. 2016; 27(4): 81-9.

48. Thorisson GA, Smith AV, Krishnan L, Stein LD. The International HapMap Project web site. Genome Res. 2005; 15(11): 1592-3.

49. Marques CS, Brito-de-Souza VN, Guerreiro LTA, Martins JH, Amaral EP, Cardoso CC, et al. Toll-like receptor 1 N248s singlenucleotide polymorphism is associated with leprosy risk and regulates immune activation during mycobacterial infection. J Infect Dis. 2013; 208(1): 120-9.

50. Barrett JC, Fry B, Maller J, Daly MJ. Haploview: analysis and visualization of LD and haplotype maps. Bioinformatics. 2004; 21(2): $263-5$.

51. Duggal P, Gillanders EM, Holmes TN, Bailey-Wilson JE. Establishing an adjusted p-value threshold to control the family-wide type 1 error in genome wide association studies. BMC Genomics. 2008; 9: 516.

52. Grant AV, Cobat A, Van Thuc N, Orlova M, Huong NT, Gaschignard J, et al. CUBN and NEBL common variants in the chromosome 10 p13 linkage region are associated with multibacillary leprosy in Vietnam. Hum Genet. 2014; 133(7): 883-93.

53. Oliveira PRS, Dessein H, Romano A, Cabantous S, de Brito MEF, Santoro F, et al. IL2RA genetic variants reduce IL-2-dependent responses and aggravate human cutaneous leishmaniasis. J Immunol. 2015; 194(6): 2664-72.

54. Schurr E, Gros P. A common genetic fingerprint in leprosy and Crohn's disease? N Engl J Med. 2009; 361(27): 2666-8.

55. Franke A, McGovern DPB, Barrett JC, Wang K, Radford-Smith GL, Ahmad T, et al. Genome-wide meta-analysis increases to 71 the number of confirmed Crohn's disease susceptibility loci. Nat Genet. 2010; 42(12): 1118-25.

56. WHO - World Health Organization. Summary of global update on preventive chemotherapy implementation in 2016: crossing the billion. WER. 2017; 92(40): 589-608.

57. de Vries JL, Perry BH. Leprosy case detection rates by age, sex, and polar type under leprosy control conditions . Am J Epidemiol. 1985; 121(3): 403-13.

58. Guerra-Silveira F, Abad-Franch F. Sex bias in infectious disease epidemiology: patterns and processes. PLoS One. 2013; 8(4): e62390.

59. Monot M, Honore N, Garnier T, Zidane N, Sherafi D, Paniz-Mondolfi A, et al. Comparative genomic and phylogeographic analysis of Mycobacterium leprae. Nat Genet. 2009; 41(12): 1282-9. 